\title{
New Knowledge and Micro-level Online Organization: 'Communities of Practice' as a Development Framework
}

\author{
Elisabeth Davenport, Hazel Hall \\ School of Computing \\ Napier University \\ Edinburgh EH4 1DJ
}

\begin{abstract}
The role of communities of practice in knowledge creation is recognised in a number of contexts. The authors take a socio-technical perspective and identify four characteristics of such communities: situated learning, situated action, distributed cognition and social infrastructure. These are combined into a loosely normative framework to define and analyse communities of practice at the level of online micro-organisation. The framework is applied to three development projects: a reference service, a virtual enterprise initiative and a simulation of an electronic shopping mall. The authors discuss its potential in explaining and stimulating new knowledge in micro-level online work environments.
\end{abstract}

\section{Introduction}

Malone and Laubacher [1] reflecting on what they call the 'e-lance economy', describe a world where the traditional hierarchical corporation has been replaced as the exemplar of organizational work by a new organisational order of networked small organizations, which must be able to rapidly configure resources and tactics in the interests of both change (when required) and consolidation. Others have corroborated this vision in reviews of 'drivers' of the virtual and knowledge economies. [2; 3; 4] In such an environment, expertise may be best acquired and nurtured in communities of practice that persist across space and time and are independent of the functional and contractual boundaries that shape participation in fixed-term teams or projects. The text that follows explores the proposition that the community of practice, a form of 'bounded' social interaction, is a locus of knowledge creation in this new organisational order. For some years, the authors have explored online communities in a number of different contexts. Much of this work was concerned with 'hybrid' groups, where online sustains or complements traditional community interaction. Online interaction may strengthen traditional community in different ways. It may make interactions more visible, for example, and thus extend the reach of individual community members [5], or it may sustain interaction when individuals are separated by circumstances or location [6]. In such hybrid communities, learning how to be a member 'in good standing' often depends on direct observation. Recently, with colleagues at Napier University and Indiana University, we have turned our attention to communities that are exclusively online, and to ways in which knowledge is created and represented in such circumstances. In this paper, three different online 'communities of practice' are discussed, with a specific focus on the infrastructure and artefacts that support new knowledge.

\section{Communities of practice: critical components}

Communities of practice have recently been defined as 'A flexible group of professionals, informally bound by common interests, who interact through interdependent tasks guided by a common purpose thereby embodying a store of common knowledge'. [7, p. 166]. Their contribution to innovation has been recognised for a number of years: Constant [8] discusses their role as an entrepreneurial frame that contributes to the "creation of novel, holistic macrosystems' (p. 224). A body of work in the last two decades is pertinent to analysis of communities of practice as a factor in knowledge creation. One strand of this is concerned with apprenticeship, or situated learning [9], which schools members of a community in how to comport themselves. A second pertinent set of studies discusses micro-level innovations in practice, or situated action [10], and shows how solutions to local problems are found and appropriated in communities. Further strands are concerned with distributed cognition [11] and the infrastructure [12] that supports situated learning and situated action by means of appropriate artefacts and ethical norms. In the text which follows, all of these are invoked as components of online communities of practice which distinguish them from other sets of online 
interactions.

\subsection{Situated learning: acquiring knowledge of practice in new contexts}

Early studies of 'situated learning' discuss highly physical workplaces: midwifery, butchery, check-out desks, and the nature of the knowledge transferred and acquired in context, face to face and over time. What the studies share is the search for insight into how novices gain multiple understandings of practice in the workplace that are characteristic of mature employees and that are largely acquired informally. In the field of education, situated learning underpins a number of pedagogical approaches with different names (deep learning, learning by doing, action learning) that attempt to offer rich simulations of the world within a secure and secluded learning environment. A novice learns by observation, by shadowing, by asking on the spot: a major component of situated learning is learning how to behave in a given group and understanding what resources to use for which purpose - recognising cues, knowing which form to use, understanding when to cut corners. Learner and teacher seek to establish comparable understandings of each one's expectations of the other. Fleming, for example, states that "situated learning draws on the "ordinary, everyday, finely detailed methodic practices of participants to an activity in specific settings" [13 p. 525) and learning, in this context, means being able to participate appropriately in the settings ... "where the subject or discipline is being done" (p. 526).

Fleming suggests that situated learning can be disassembled into constituent parts, using the following:

-a structural anatomy -- how are sequences of actions assembled and constructed in the specific settings in which they are used

-a functional anatomy -- the use to which methodic practices are put on a given occasion

-an understanding of the machinery which produces practice -- how do descriptions, facts, processes work together to produce what participants in the dialogue recognize as an explanation of the phenomenon in question?

In this way, a 'tacit' process, learning, may be made amenable to formal description, which may enrich the process of apprenticeship in the world described above, where rapid turnover of staff and projects compresses time frames. While acknowledging Star's caveat [14] that over-formal representation can inhibit flexibility in organisation, we believe that such representations have value. They may contribute to reflective practice, by capturing material to prompt self-evaluation, and may be the basis of 'virtual apprenticeship' [15] or knowledge of how to behave in new environments in online communities.

\subsection{Situated action: creating new practice}

The importance of communities of practice for local problem solving in ad/hoc unforeseen contingencies has been established in a number of micro studies. Several of these have emerged from Xerox Corporation, where, for at least a decade, managers have endorsed and encouraged communities of practice as major sites of innovation. The photocopier is the specific locus of innovation in case studies of Xerox engineers [16] and office workers [10], where micro level adaptations are shown to lead to design modifications in major company products. A number of different social interactions are brought into play in these scenarios - dialogue and narrative exchange, validation of the innovation - which are repeated at different levels of organisation. A comparable pattern can be observed in examples of innovation in the Japanese organisations described by Nonaka and his colleagues [17], whose SECI (socialisation, externalization, combination, internalization) model, an acknowledged framework for management practice at Xerox, describes the oscillation of public and private, tacit and explicit knowledge in innovative firms. In many of these cases, innovation is seeded by situated action, and embedded in practice by subtle processes of entrainment.

Situated action has provided a useful theoretical framework for analysing innovative micro level responses to organisational blockages and breakdowns in a number of other contexts. Typically such work is invisible, as it is what Gerson and Star [18] call 'articulation' work, that is activity that gets things done at local level and thus fulfils expectations at a higher organisational level that things are going smoothly.

In the world of clinical practice, for example, much articulation work is undertaken by nurses, and nursing has served as a ready context for the exploration of concepts like legitimacy, authority, and recognition. A number of studies [19; 20] have examined the development of a domain classification, the Nursing Intervention Classification [NIC], and analyzed the process of legitimation and the nature of the political economy which underlies such legitimation activity. Nursing may serve as an exemplar of a community of practice that has had to struggle to have innovations made at local level recognised in the broader domain of therapeutic intervention [21].

\subsection{Distributed cognition: the division of knowledge across tasks and artefacts}

Distributed cognition, or the division of cognitive labor 
across people and artefacts in groups completing collective tasks has been explored in a number of communities of practice, online and offline. In several exemplary studies, Hutchins $[11 ; 22 ; 23]$ anatomises teamwork in tight corners (the bridge of a ship; a cockpit) and demonstrates that collective outcomes are achieved on the basis of a cognitive chain reaction. Cook and Yanow describe a similar process in the very different context of flute-making [24; 25] The artefact ('the flute') emerges from a sequence of activities performed by specialist artisans, each of whom contributes unique expertise, which is only valuable as part of the collective process of construction. Each contribution is validated by the 'feel' of the product as it passes from hand to hand; cumulating knowledge is embedded in the product, which embodies the knowledge of the group. Recent work on flight control that is pertinent to online communities of practice has been undertaken in the interests of designers. Wright et al. [26] have explored the information that pilots share when changing shifts and its implication for the design of automated cockpits, and a number of studies have explored the use of paper strips in flight control rooms [27] again in the context of proposed automation of the tasks that characterize this specialist community. Perry [28] has recently analyzed a group of civil engineers on a construction site using distributed cognition as an explanatory framework.

\subsection{Social infrastructure: providing common ground for innovation}

We have identified three knowledge practices as important in communities of practice: distributed cognition, knowledge of how to participate and be a member in 'good standing' of a community, acquired in situated learning, and knowledge of how to proceed in the face of local difficulties, acquired in situated action. Each is sustained by appropriate infrastructure - both infrastructure that consolidates knowledge and infrastructure that allows knowledge to be diffused. Assuming technological infrastructure as 'given' in discussions of online communities of practice, we use the term 'social infrastructure' here, adapting the work of Star and her colleagues [12], to embrace:

* 'boundary' infrastructure, or the objects that are instantiated by such ICTs and that may be shared by member of a group and across groups

*'network' infrastructure or the networks that are brought into play to establish, maintain or enhance position or status

* 'narrative' infrastructure.

\subsubsection{Boundary infrastructure}

In face to face communities like that of the flutemakers described above, representation of collective knowledge is not an issue. Where members of groups are dispersed in space (across a site, for example, or in cases where they are members of different workshifts), representation may be a critical issue. It is equally critical where transdomain understanding is at stake, or 'hybrid' cognitions are in play: Salomon, for example, [28] states that there can be no distributed cognition without individual cognition, and that many 'cognitions' are not distributed. A relational schema that accommodates individual and group knowledge may thus be an important bridge within and across local knowledge regimes.

Where such schemes are designed to support interdomain understanding [29], they may be considered as 'boundary objects' [30] a class of objects provide common ground for different social actors to work together. They may be artefacts, texts, prescriptions, classification systems, indexes, and both 'protean' and 'robust' Individuals may also be part of boundary infrastructure, where they contribute to the diffusion of knowledge across and between communities (the traditional 'gatekeeper' role). One approach is to foster a specific organizational role, 'the broker'. This role within in the firm is treated in depth by Wenger [31, pp. 235236], who classifies brokers into three types: 'boundary spanners', 'roamers', and 'outposts'. In addition to boundary objects and brokers, Wenger discusses 'boundary interactions' as an important feature of the diffusion process, and suggests that these can be managed or harnessed in the interests of innovation. (pp. $236-8$ ). He offers examples of simple mechanisms (online and offline): off-site sabbaticals, visits, seminars, and on-site help desks, FAQ lists, 'visiting rooms' and fairs. In the cases that we present below, we can identify brokers and boundary objects (in the shape of interfaces and genres for example, that characterize interactions).

\subsubsection{Network infrastructure: ties and interpersonal trust}

We have some understanding of network infrastructure after a decade of studies of social network analysis, and of trust in organizations. The nature of the bonds and relationships that link members of online communities of practice can be explored with the help of a body of work on computer supported communities, specifically work by Wellman and his colleagues $[32 ; 33]$, which suggest that participants in both offline and online networks operate within a portfolio of relationships, whose intensity and density varies according to their purpose in belonging to the network. Lewicki and Bunker [34] have modelled the development of interpersonal trust as a three phase process, which moves from 'calculus' to 'knowledge' to 
'intimacy' over time. Ties are likely to be strong where members of a community of practice have bonded in apprenticeships (traditional 'situated learning') in closed communities. Powell, however, in a study of trust and governance [35], suggests that trust is not an outcome of calculus, nor a culture-bound variable, but emerges in interactions. It is 'neither chosen nor embedded, but learned and re-inforced, hence (is) a product of ongoing interaction and discussion' (p. 63). This raises the issue of whether group interactions where time is short and bonding is attenuated may qualify as communities of practice?

\subsubsection{Narrative infrastructure}

Deuten and Rip [36] use the term 'narrative infrastructure' to capture "the evolving aggregation of actors/narratives in their material and social setting, that enables and constrains the possible stories, actions and interactions by actors" in organizations. (They thus corroborate the observations of a number of other analysts who stress that 'story-telling' is an important factor in community cohesion). In explaining how coherence can emerge in a multi-actor, multi-level process, without any actor specifically being responsible. Deuten and Rip stress that narration, rather than text, must be the focus of attention, because 'narration occurs in interactions, informs and shapes them and makes action into something memorable'. By analyzing 'narrative infrastructure' in a case study of product innovation in a biotechnology firm, they show 'how actually, over time, attribution and typicifaction in stories, and the implied stories contained in interactions link up, and an overall plot emerges' ( $p$ 69). Suchman and Trigg offer a comparable account of 'pseudo-narratives' in an AI community of practice that 'are constructed for the specific purpose of reconstructing common sense knowledge as something that can be transparently read off of the particular technical representations to hand' . [37, p. 177]

Work by Berkenkotter [38] on 'boundary rhetoric' is relevant to discussion of narrative. Berkenkotter draws on work by Fuller [39] on interdisciplinary 'interpenetration', 'trading zones' and 'boundary rhetoric', and describes disciplines (or, as is the case here, communities of practice) as "contingent groupings of practitioners situated in multiple networks determined by such factors as objects of study, theories, methodologies, epistemological alliances, institutional sites and funding arrangements' [24, p. 177]. Boundary rhetoric, says Berkenkotter, is primarily designed to accommodate disciplinary differences, which it does by means of 'the creation of a heteroglossic text' (p. 179). 'Key informants', trusted authorities in a number of fields (c.f the middle managers or brokers identified as cross-fertilising agents in some of the knowledge management literature), can play an important role in enlisting and enrolling allies to support emerging rhetorics.

\section{Case Studies: the 'community of practice' framework at work}

In the text so far, four significant components of knowledge creation in communities of practice have been identified: situated learning ('SL') or learning how to be a competent member of the community; situated action ('SA'), or creative solving of local problems, distributed cognition ('DC'), or the chain of interaction with artefacts and people that leads to collective knowledge, and social infrastructure ('SI') specifically the provision of boundary objects and the development of social and narrative infrastructure. Much of what is understood about these processes comes from studies of 'material' organizations, and physical workplaces. In the text that follows, we discuss three projects whose objective is to foster new knowledge in micro-level online communities. We have used the four SL, SA, DC and SI components as a loosely normative framework to assess the potential, given local constraints, of each of the projects as a development framework for organizational knowledge. The community of practice ('COP') framework is minimal: we are aware of critiques of Wenger's highly specific 'performative' criteria for communities of practice [40].

\subsection{Community One: an online reference service}

In the first study, the reference service of an academic library was taken as the locus of a 'community of practice', which embraced both experts and novices in the form of librarians and patrons. (It should be noted that experts are not commensurate with librarians, and novices are not commensurate with patrons). In 1997, this community was the focus of a pilot project for a proposed change in service, which would help the library economize on valuable expert time, by substituting a stratified online service for on-demand access to trained professionals, who would become the place of last resort. The pilot was premised on a web infrastructure, which could include video and audio conferencing, e-mail and FAQ lists. The online implementation was thus webbased, and required in its simplest form a web browser.

The project drew on situated learning as a framework for the design of innovative service. The community of practice in this project was taken to be all those involved in the consultation process, not simply the 'professional community' of librarians, or a separate community of 'users', as both groups were bound to interact with the new system. (Lamb and Kling [41] have recently presented a rationale for replacing the term 'user' with 
'interactor' which supports this methodological stance). In the new reference environment that replaced the familiar infrastructure of online catalogue and reference desk, neither users nor librarians could assume that old habits would serve them well, and all would have to learn new practice. The pilot design attempted to accommodate shifts in knowledge of 'how to proceed'. Cues on what moves to make were presented in the form of 'boundary objects' of various kinds, such as menus, FAQ lists, and email messages. In terms of Fleming's framework, invoked earlier in the text, 'situated learning ', means 'being able to participate appropriately in the settings ... where questions are being asked'. In the world of the traditional reference interview, the 'user' has to figure out how the system works, and, with the help of a librarian, frame questions that meet system requirements. In a remote reference consultation setting, a greater burden is borne by the librarian, who has to figure out the habitat of the patron, or what is happening at the desktop.

The design team focused on two ways of accelerating the 'situated learning' process. In the first, insights from genre analysis were used to restrict the 'boundary objects' offered online to a few familiar forms appropriate to the three 'master' genres that characterized reference work in this institution: the 'classic' interview, the helpdesk, and peer assistance. As Yates et al. observe, [42] genre is an appropriate object of study in communities of practice, because 'genre systems' can be identified within established communities: these are characterized by "an interrelated sequence of genres enacted by members of a particular community ... composed of a well-co-ordinated set of communicative moves that together accomplish an interaction' (p. 51). In the case of the classic reference interview, for example, the 'community' is that of patrons and professionals, the communicative 'moves' are the phases of the on-line reference interview, the 'interaction' is the shared search, and the purpose and form are the provision of information within the institution of the library.

In this project, the possible role of peers in the creation of new knowledge, and in the production of new genres was recognized. In addition to the boundary objects listed above, the team included the provision of user histories in the design specification. These have proved effective as 'boundary objects' in a number of contexts. Twidale and his colleagues [43] propose visualization of 'instant history' as a key to fast profiling . This may greatly accelerate both user and expert understanding of what sequence of actions has led what position. User histories may be saved to provide archives of cumulated individual behavior (just like FAQ archives). As this project was a pilot project only, and funded under a technology development programme, detailed testing of the system and its surrounding community was not done.

It is clear that not all members of such a community (casual enquirers, for example) are participants in a community of practice. Where, however, interaction with the system is part of a sustained project carried out collaboratively (the preparation of a group assignment, the sourcing of a research project) within a subject domain, a COP framework is a pertinent analytic tool. We suggest that 'practice' in such cases is 'using the online system to source the task in hand', and that the 'community' is those interacting with the system, their peers or colleagues, and library staff. As we indicate above, the system was designed to support some of the constituent elements of a COP framework, though it was weak on network and narrative infrastructure. (The latter might be overcome by using personal 'stories' in addition to visualizations of transaction logs in the archive of user histories). With hindsight, we can see that several improvements might be made. Explicit development of separate domain histories and system histories might be useful, to disentangle technical fixes from issues of 'material mastery', Covi's term [44] for competent interaction with domain documentation.

A comparable digital library project in the University of Illinois, with systematic evaluation, has recently been reported. This work was also grounded on 'communities of practice' but focused on subject domain as the 'community', and emphasised 'user meets infrastructure' rather than situated learning as a mechanism for intensifying digital library use. [45]. To the surprise of the researchers, users did not take advantage of a rich affordance modelled closely on the details of individual working habits. We suggest that a design approach using a COP framework that focused as much on the 'reference situation' as on user profiles and thus acknowledged that most of us belong to multiple COPS, might overcome reported shortcomings in both the Edinburgh and Illinois projects.

\subsection{Community Two: virtual enterprise}

The second project is an EC funded initiative which aims to create a learning framework for small enterprises in the European tourism sector. The project is intended to foster the formation of highly localized 'virtual enterprises' that may promote local regions as tourism destinations. In terms of a COP framework, the 'practice' of these groups is collective destination management, and the 'community' is a virtual enterprise comprising individual small firms who must work together as collective intrapreneurs. The project is in the hands of an international consortium, who have designed a portfolio of learning 'units' that are designed to 'entrain' managers working with a COP learning framework, which will 
prepare them for their subsequent interaction in the COPs that constitute a regional virtual enterprise. In taking this approach, the project team conform with Wenger's [31] advice that COPs should be seen as a fractal phenomenon, and that small COPs will themselves participate in, and augment distributed cognition, in larger COPs.

The Net Quality team are aware of the fallacy, exposed in a number of studies [e.g. 46], that an extranet or intranet with some basic tools can lead per se to identifiable structural and procedural transformation. They have thus taken considerable care to design a learning platform which can work on a number of different infrastructures (e.g. FirstClass, Learning Space, Microsoft Outlook, MUSIC (a multimedia learning platform developed with support form an earlier EC project), or local bricolages). The team have identified a core suite of units, each of which is based on a standard business question: 'How can I make myself more visible?' for example, or 'How can I build up my social network?' Each of the units has been designed to conform with a common template or 'learning shell', which takes a work-based and problem-based learning approach, and which can be delivered in online, or offline/online hybrid mode.

The first phase of each unit establishes an 'SL' environment, by capturing the expectations and motivations of participants, and introducing them to the 'ways' of the unit: the tools, processes and the etiquette that shape the online learning space. The design rationale is heavily influenced by the work of Gherardi et al. [47] Participants will use narratives of their own experience ('SA') as a starting point in answering the questions. The role of the 'broker' or tutor ('SI') has been carefully constructed. Tutors are responsible for managing distributed cognition ('DC') by shaping and archiving the insights that emerge as learners work first in pairs, then in larger groups, to provide suggestions and insights on the problem areas. At each stage, the output from groups will be archived for 'social learning' ('SI') purposes.

The tutor will handle the issue of how the learners should appropriate exogenous knowledge (produced by other learner groups, or insights of outside experts in the form of best practice) taking account of the disposition of each learning group. Both endogenous and exogenous narratives can be archived, and (where appropriate) assembled with the help of course tutors into 'patterns' of the kind currently invoked in a number of knowledge management studies. [48] As we indicate above, the templates are intended to 'entrain' learners into working as a 'community' to address the questions that comprise the unit topics.

The remit of the Napier team includes the development of a 'social networking' unit. One component of this unit covers partnership, and the Napier team have adapted work from a previous EC project to design a 'social browsing' module. In the earlier project [5], the goal was to build an infrastructure that would allow the processes of situated learning and trust building to be compressed, in cases where ad hoc teams, working remotely, need to be configured rapidly. In the current project, considerable thought has been given to the provision of scenarios that allow prospective participants to assess how well distributed cognition might work in the proposed partnership. Learners will be encouraged to use the COP framework in this part of the module, as we feel that it may facilitate such evaluation of partners.

By January 2001, a number of units will have been tested with practitioners, and we intend to provide a brief demonstration of at least one of the units in our session. Though the components of Net Quality have been specifically designed to incorporate SL, SA, DC and SI in a COP framework, we cannot fully evaluate the efficacy of that framework in the short term. We are seeking further funding to implement the learning scheme across the tourism sector in Scotland on a long-term basis, which will allow us to assess the insights and innovative practice (if any) that emerge.

\subsection{Community Three: e-tail}

In the third project, the 'community' consisted of a class of graduate and undergraduate students; the 'practice' was learning to be an e-consumer. As part of this process, students were faced with ill-structured problems that engaged their knowledge, skills, and attitudes over the semester. Because shoppers visited the mall and purchased products for eight weeks, there were real-world benchmarks against which students' work was evaluated (sales, repeat customers, traffic reports, and customer feedback). Students worked in small groups in an asynchronous, self-paced and situated learning environment using shared workspaces and multiple communication channels to develop collaborative solutions to the tasks in hand.

The mall is a password-protected web space (which continues to be supported in Indiana University) where participants conduct business transactions under conditions simulating real-world business-to-consumer ecommerce The stores sell information to students who must complete term papers on given topics. A prototype was built using HTML, Cold Fusion, and Oracle. The prototype has four main components, which work through established e-commerce genres. The first is the portal, the entryway to the marketplace. Shoppers register, receive passwords and digital bank accounts, and then browse the storefronts. There are ad banners on the portal page that allow shoppers to click through to the stores. The second component is the storefront. The basic template for each 
store is a web page with a custom Cold Fusion tag $<$ cf_store $>$ that contains a product catalog, a shopping cart, and a checkout procedure. The shopping cart passes persistent data throughout the store. Shoppers can check out, change quantities, remove items from the cart, or can opt out of the entire transaction. Store teams begin with the same basic template and must distinguish themselves through design and product and service offerings.

The third component is a digital bank, with accounts for both shoppers and stores, and accounts that are dynamically adjusted when the transactions take place. The bank is relatively secure - shoppers and storeowners can check their balances but do not have access to each other's accounts. The fourth component is the digital product warehouse. Each store has a password-protected storage area on a server where the information products can be uploaded. Each store also has an email account and a web-board that can be used in any way the store team sees fit.

As instructors we wished to know what students would learn about web shopping under the conditions that we describe above, and whether 'spontaneous' COPs would emerge. This project differs from the two previous ones in that 'learners' were left to their own devices. Though a technological infrastructure was set up that had the potential to serve as a 'social infrastructure', students were not specifically 'inducted' to use it in this way. And though they were separated into 'theme' groups for the purposes of preparing for the class assignment, they were not assessed on their contributions to social learning, or even overtly encouraged to practice distributed cognition. All students signed a consent form making available for research analysis the records of class activities (captured in the archive of electronic interactions, and in diaries preand post-course questionnaires) which gave us some insight into community practice such as it was.

The mall was open to shoppers (students from Napier University Business School in Edinburgh) between February and April. As a pre-shopping questionnaire revealed that most students had little experience of eshopping, they served time in a two-week 'apprenticeship' on two commercial sites, supported by a teaching homepage on e-commerce web design and ecommerce genres. Though several 'pairs' of students collaborated in shopping across vendors, and in dividing the labour that they perceived was required to prepare for their individual assignments, only one group formed an embryonic COP. This was largely as a result of the efforts of one individual who acted as a classic broker demonstrating how collaborative activity might work ('SL') and making sure that 'nifty' bargaining strategies ('SA') were shared across the group. This individual established a weblist for his group ('DC') which was made available to others working on different topic areas.
Did this contribute to new knowledge? Our only measures are indirect: the course assignments produced by members of this COP were more informative and were supported by a wider range of references than those of their colleagues, and the diaries of the group were more enthusiastic than their colleagues about the class experience.

\section{Conclusion}

The community of practice (COP) is a socio-technical form that can both explain and stimulate the creation organizational knowledge. Its explanatory power where members of a community are self-motivated has been established in the studies 'in the wild' of situated learning, situated action and distributed cognition that are invoked in the early sections of this paper. A COP reveals how new knowledge is created because a COP is formed by means of social interactions that lead to collective knowledge. Less well established is the extent to which a COP stimulates new knowledge where infrastructure is put in place in place to promote COP components (SL, SA, DC).

As instructors in the case of community three, we have learned that COPS do not always emerge even though conditions are favorable: learners (organizational or otherwise) may require guidance before they can work synergistically though a COP. We were aware of a rich literature on web shopping, and on the exploitation by vendors of consumer groups as important sources of insight and knowledge [49]. Web-shoppers and web vendors, however, present an interesting challenge to the 'community of practice' framework, as the communities involved may be highly specific (as in e-Bay), and, in some cases, extremely short-lived.

In some published reports of online shopping groups, components of the COP framework have been described: some kind of apprenticeship, micro level situated action that solves ad hoc problems, and 'boundary objects' in the form of supportive artefacts: genres like the webring, for example, recommender systems, and track records (as in e-pinions). In addition, a social infrastructure for webshopping may be supported by agents and brokers [50] who can partner those with shared tastes or partner consumers and products, and capture and disseminate the insights that consumers provide either across communities of practice, or to vendors and designers. Such a scenario raises issues of community integrity: can members of a community contribute 'involuntarily' to distributed cognition?

Just how much guidance on how to participate is required, and what new knowledge may emerge are areas for further research. The project with SMEs in Community Two may improve our understanding of what 
kinds of intervention contribute to COP formation. The COP framework can support such an agenda, as it draws on the explanatory tradition to provide a loosely constrained environment for exploratory interventions. It is also useful at the simple level of definition. Not all online communities are communities of practice, [51; 52]. If SL, SA, DC and SI are indeed distinctive features of COPs we can benchmark other online groups against them, such as the socio-technical interaction networks recently described by Kling and his colleagues [53].

\section{Acknowledgments}

The authors acknowledge the support given to part of this work by DGXIII 98006361/IT-9. They also wish to thank Howard Rosenbaum for his contribution to the technical account of the shopping mall, and students in Indiana University and Napier University Business School who have participated in that project.

\section{References}

[1] Malone, T. and Laubecher, R.J., "The dawn of the e-lance economy," Harvard Business Review, September - October, 1998, pp. 145-152.

[2] De la Mothe, J. and Paquet, G., "Information innovations and their impacts," Information, innovation and impacts, ed., J. De la Mothe and G. Paquet, Norwell, MA, Kluwer Academic Publishers, 2000, pp. 5 - 34.

[3] Igbaria, M., "The driving forces in the virtual society," Communications of the ACM, 42 (12), 1999, pp. 64 - 69.

[4] Levy, P., Becoming virtual: reality in the digital age, New York, Plenum Trade, 1998.

[5] Davenport, E. et al., "Making interactions visible: tools for social browsing," Documents de travail. Le Travail Humain. 7eme Atelier, Paris, 14 September, ed., P. Marti, and S. Bagnara, 1998.

[6] Hall, H., "Recreating community: a virtual case study," Education for Information. 17, 1999, pp. 253-258.

[7] Jubert, A., "Developing an infrastructure for communities of practice: the Siemens experience," Online Information 99 Proceedings, Hinksley Hill, Learned Information Europe, 1999, pp. $165-168$.

[8] Constant, E. "The Social Locus of Technological Practice: Community, System or Organization?" The Social Construction of Technological Systems, ed. W. Bijker, T. Hughes and T. Pinch, Cambridge, MA, MIT Press, 1989, pp. 223 - 242.
[9]. Lave, J. and Wenger, E., Situated learning: legitimate peripheral participation, Cambridge, Cambridge University Press, 1991.

[10] Suchman, L., Plans and situated actions: the problem of human-machine communication, Cambridge, Cambridge University Press, 1987.

[11] Hutchins, E., "The social organization of distributed cognition," Perspectives on socially shared cognition, ed., L.R. Resnick et al., Washington DC, American Psychological Association, 1991, pp. 284 - 307.

[12] Star, S. L. and Ruhlehder, K., "Steps Towards an Ecology of Infrastructure: Complex Problems in Design and Access for Large-Scale Collaborative Systems," CSCW '94: Proceedings of the Conference on Computer-Supported Cooperative Work; 1994 October 22-26; Chapel Hill, NC, ed. R. Furuta and C. Neuwirth, New York, ACM, 1994, pp. 253 - 264

[13] Fleming, W.G., "Methodography: the study of student learning as situated action," Learning approaches evaluation and strategy. Improving student learning through assessment and evaluation, ed. G. Gibbs, Oxford, Oxford Brookes University, 1994, pp. 525-544.

[14] Star, S. L., "The politics of formal representations: wizards, gurus, and organizational complexity", Ecologies of knowledge: work and politics in science and technology, ed., S. L. Star Albany, State University of New York Press, 1995, pp. 88 - 118.

[15] Davenport, E. and Cronin, B., "The virtual apprentice," Journal of Information Science, 17(1), 1991, pp. 65 - 70.

[16] Brown, J. S. and Duguid, P., "Organizational learning and communities-of-practice: toward a unified view of working, learning, and innovation," Organization Science, 2 (1), 1991, pp. $40-57$.

[17] Nonaka, I. and Konno, N., "The concept of 'Ba': building a foundation for knowledge creation," California Management Review, 40 (3), 1998, pp. 40-54.

[18] Gerson, E.M and Star, S.L, "Analyzing due process in the workplace," ACM Transactions on Office Systems , 4(3), 1986, pp. 257-270.

[19] Bowker, G., Timmermans, S. and Star, S.L., "Infrastructure and organizational transformation: classifying nurses' work," Information technology and changes in organizational work. Proceedings of the IFIP WG8.2 working conference on information technology and changes in organizational work, December 1995, ed., W. J. Orlikowski, G. Walsham, G., M.R. Jones, and J. I, DeGross, London, Chapman and Hall, 1995, pp. 344-370.

[20] Bowker, G. and Star, L., Sorting things out, Cambridge, MA, MIT Press, 1999, pp. $230-254$. 
[21] Davenport, E.. "Translating texts into care: classification issues raised by evidence-based practice in the UK Health Service", Proceedings of the 9th ASIS SIG/CR Classification Research Workshop, October 35 1998, ed., E. Jacob, 1998, pp. 53-70.

[22] Hutchins, E., Cognition in the wild, Cambridge, MA, MIT Press, 1995.

[23] Hutchins, E., "How a cockpit remembers its speeds,"Cognitive Science, 19, 1995, pp. 265 - 288.

[24] Cook, S. and Yanow, D., "Culture and organizational learning," Journal of Management Enquiry, 2 (4), 1993, pp. 373-390.

[25] Wright, P., Pocock, S. and Fields, B., "The prescription and practice of work on the flight deck," Understanding work and designing artefacts. Proceedings of a workshop, 21 September 1998, King's Manor, University of York, ed., P. Wright and B Fields., York, University of York Department of Computer Science, 1998, 7 pp.

[26] Mackay, W., "Is paper safer? The role of paper flight strips in air traffic control," ACM Transactions on Computer-Human Interaction, 6 (4), 1999, pp. 316 - 340.

[27] Perry, M., Process, representation and taskworld. distributed cognition and the organisation of information. Exploring the contexts of information behaviour. Proceedings of the Second International Conference on Research in Information Needs, Seeking and Use in different contexts. 13/15 August 1998. Sheffield, UK, ed., . T. D. Wilson and D.K. Allen, London, Taylor Graham, 1998, pp. 552 - 567.

[28] Salomon, G. "No distribution without individual's cognition: a dynamic interactional view," Distributed cognitions, ed., G. Salomon, New York, Cambridge University Press, 1993, pp. $111-138$.

[29] Albrechtsen, H. and Jacob, E.K., "The dynamics of classification systems as boundary objects for cooperation in the electronic library," Library Trends, 47 (2), 1998, pp. 293 - 312.

[30] Star, S.L. \& Griesemer, J.R., "Institutional ecology,'Translations' and boundary objects: amateurs and professionals in Berkeley's Museum of Vertebrate Zoology, 1907-1939,” Social Studies of Science, 19, 1989, pp. 387-420.

[31] Wenger, E., Communities of practice: learning, meaning, and identity, New York, Cambridge University Press, 1998.

[32] Wellman, B. and Gulia, M., "Virtual communities as communities: Net surfers don't ride alone," Communities in cyberspace, ed., M. Smith and P. Kollock, London, Routledge, 1999, pp. 167 - 194.

[33] Garton, L., Haythornthwaite, C. and Wellman, B., "Studying on-line social networks," Doing Internet research: critical issues and methods for examining the net, ed., S. Jones, London: Sage Publications Inc., 1998, pp. 75 - 106.

[34] Lewicki, R.J. and Bunker, B.B., "Developing and maintaining trust in working relationships," Trust in organizations: frontiers of theory and research, ed., R.K. Kramer, and T.R. Tyler, London, Sage, 1996, pp. 114 - 139.

[35] Powell, W., "Trust-based forms of governance," Trust in organizations, frontiers of theory and research, ed., R.K. Kramer, and T.R. Tyler London: Sage Publications, 1996, pp. $51-67$

[36] Deuten, J.J. and Rip, A. , "Narrative infrastructure in product creation processes," Organization, 7 (1), 2000, pp. 69 93.

[37] Suchman, L. and Trigg, R., "Artificial intelligence as craftwork," Understanding practice: perspectives on activity and context, ed., S. Chaiklin and J. Lave, Cambridge, Cambridge University Press, 1993, pp. 144 - 178.

[38] Berkenkotter, C., "Theoretical issues surrounding interdisciplinary interpenetration," Social Epistemology, 9 (2), . 1995, pp. 175-187.

[39] Fuller, S., Social Epistemology, Bloomington, IN, Indiana University Press, 1988.

[40] Contu, A. and Willmott, H., "Comment on Wenger and Yanow, Knowing in practice: a 'delicate flower' in the organizational learning field," Organization, 7 (2), 2000, pp. 269-276.

[41] Lamb, R. and Kling, R., Social interaction through information and communication technology: reconceptualising users, 2000, available at: http://www.slis.indiana.edu/kling

[42] Yates, J., Orlikowski, W. and Rennecker, J., "Collaborative genres for collaboration: genre systems in digital media," Proceedings of the Thirtieth Hawaii International Conference on System Sciences (HICSS-30) Volume VI. Digital Documents Track, ed., R. Sprague, Los Alamitos, CA, IEEE Computer Society Press, 1997, pp. 50 - 59.

[43] Twidale, M. and Nichols, D., "Collaborative browsing and visualisation of the search process," Aslib Proceedings, 48 (7/8), 1996, pp. 177-182.

[44] Covi, L., "Material mastery: situating digital library use in university research practices," Information Processing and Management, 35, 1999, pp. 293 - 316.

[45] Bishop, A. et al., "Digital libraries: situating use in changing information infrastructure," Journal of the American Society for Information Science, 51 (4), 2000, pp. 394-413.

[46] Newell, S., "Ebank: a failed knowledge management initiative," Case studies in knowledge management, ed., $\mathrm{H}$. 
Scarborough, London, Institute of Personnel and Development, 1999, pp. $24-34$.

[47] Gherardi, S. Nicolini, D. and Odella, F., "Toward a social understanding of how people learn in organizations: the notion of situated curriculum," Management Learning, 29 (3), 1998, 3 pp. 273 - 298.

[48] Falconer, J., "The business pattern: a new tool for organizational knowledge capture and reuse," ASIS '99: Proceedings of the 62nd ASIS Annual Meeting, Volume 36, 1999, Washington DC, October 31 -

November 4 1999, ed., L. Woods, Medford NJ, Information Today, Inc., Inc., 1999, pp. 313 - 330.

[49] McWilliam, G., "Building stronger brands through online communities," Sloan Management Review, Spring, 2000, pp. 43 54.

[50] Maes, P., Guttman, R. and Moukas, A., "Agents that buy and sell," Communications of the ACM, 42 (3), March, . 1999, pp. 81-91.

[51] Bobrow, D. G., "3C or not 3C, that is the question," SIGGROUP Bulletin, 18 (1), April, 1997, pp. 33 - 35

[52] Mynatt. E.D., Adler, A., Ito, M. and O'Day, V., "Design for network communities," Proceedings of CHI 97, New York, ACM, 1997, pp. $210-217$

[53] Kling, R. et al. , "A bit more to IT: scientific multiple media communication forums as socio-technical interaction networks," 2000, at http://www/slis.indiana.edu/SCIT 